\title{
Research on Power System Control Based on Emergency Response
}

\author{
Chen Weihua ${ }^{1,2^{*}}$, Shan Renzhong ${ }^{1,2}$, Bai Cuifen ${ }^{1,2}$, and Zhang Youdong ${ }^{1,2}$ \\ ${ }^{1}$ School of Mechanical and Electrical Engineering, North China Institute of Science and Technology, China \\ ${ }^{2}$ Hebei Key Laboratory of Safety Monitoring of Mining Equipment, North China Institute of Science and Technology, China
}

\begin{abstract}
In order to prevent power system disasters and improve power system emergency response capability, the theoretical basis of integration power system disaster prevention and emergency response into social disaster prevention and emergency response was studied. Based on the statistical summary of power system disasters and emergency treatment, the necessity and feasibility of integration power disaster prevention and emergency response into social disaster prevention and emergency response was analyzed. And the mode of integration power disaster prevention and emergency response into social disaster prevention and emergency response was discussed, including weak contact mode, integration mode, unified coordination mode, etc. Then, the path map of integration power disaster prevention and emergency response into social disaster prevention and emergency response was constructed. The research shows that integration of power disaster prevention and emergency response into social disaster prevention and emergency response can realize the prevention and early control of electronic system disasters through data sharing and action coordination, so as to improve the level of power disaster prevention and emergency response.
\end{abstract}

\section{Introduction}

The power industry is the foundation of the national economy. With the development of electrification and automation, the coupling between power and society is growing. Therefore, the security of power system has always been one of the hot research areas [1-3].

Because power system is a traditional monopoly industry, the security research of power system is often limited in the power system. The coordination with other sectors of society is lacked. Therefore, when the power system disaster, the impact on the outside world is often difficult to convey. For example, when the New York power outage broke down, traffic was paralyzed by the blackout. On the other hand, the external disaster which endangers the safe operation of power system is difficult to alert the power system quickly. For example, in Fukushima nuclear power plant accident, if the tsunami information can be effectively and timely, the accident may be avoided. At present, researchers inside and outside the power system have gradually realized the importance of coordination between electric power disaster prevention and social disaster prevention. [4-6].

This paper summarizes the results of power system disaster prevention and emergency response in recent years. The necessity of integrating power system disaster prevention and emergency response into social emergency response is analysed. The control mode of power system is put forward. This paper looks forward to the development trend of social disaster prevention and emergency response, so as to better prevent the occurrence of power system accidents and improve the safety management level of power system.

\section{Necessity analysis}

The integration of power system disaster prevention and emergency into social emergency disaster prevention is the inevitable requirement of the basic position of power, eliminating redundant construction, improving power system disaster prevention and emergency response capacity, rationalizing management and other factors [78].

Electric power is the foundation of social development. Electric power has many advantages, such as clean, efficient, easy conversion, good control and so on. It has been integrated into all aspects of social production and life. In the field of production, electric equipment can achieve high precision and automatic control. In the field of life, TV, refrigerator, electric cooker, washing machine and other household appliances have greatly improved people's quality of life. In the field of transportation, high-speed rail and motor cars all use electrified units. New energy electric vehicles also show a trend of gradually replacing traditional fuel vehicles. Therefore, the disaster prevention and emergency of power system must be included in the disaster prevention and emergency system of the whole society.

\footnotetext{
* Corresponding author: cwhwc@163.com
} 
Eliminate the redundant construction. In order to improve the ability of disaster prevention, power system has built a number of early warning and detection systems. For example, lightning information collection system can be built in the power system of lightning prone areas. Typhoon information collection system is built in the power system of coastal areas. These nonpower professional equipment or systems provide useful information for the safe operation of power system. However, the investment of these equipment or systems is large. The maintenance cost is high. Compared with the professional system, the function is single. At present, with the development of disaster prevention and emergency response in the whole society, various departments and their professional systems are gradually opening up. The power system should actively integrate into the social disaster prevention and emergency system, directly use the data of these professional systems, reduce costs, improve accuracy and enrich functions.

It is necessary to improve the ability of disaster prevention and emergency response of power system. Generally speaking, the closer the prediction model is to the risk source, the higher the prediction accuracy and the more abundant the warning time. At present, the prediction model of power system mainly takes the internal equipment of power system as the modelling object, which is not close to the risk source. And the time margin of early warning is not enough. Therefore, the power system disaster prevention and emergency into social disaster prevention and emergency, can be close to the source of disaster early warning, and actively improve the power system's own disaster prevention and emergency ability.

Rationalize the management. The power industry is a traditional monopoly industry, which mainly adopts the vertical integration operation mode. In March 2018, the state set up an emergency management department to guide all regions and departments to deal with emergencies. Therefore, the integration of power system disaster prevention and emergency into the whole society is also an inevitable requirement for the development of China's emergency cause.

\section{Feasibility analysis}

It is necessary to integrate the power system disaster prevention and emergency into the social emergency disaster prevention. From the theoretical basis, practical experience, personnel security, policy support and other aspects, it is feasible to integrate power system disaster prevention and emergency into social emergency disaster prevention [9-10].

The solid theoretical foundation has been built. Power system has always put the safe operation in the first place. A lot of theoretical research carried out. The relevant theoretical basis has been constructed so far. For example, the theory of "three lines of defences" studies the defence action of power system in different fault states. At the same time, transportation, energy and other related industries have also carried out a lot of theoretical research work in disaster prevention and emergency. They have made great progress.

Rich practical experience has been accumulated. In the field of power operation, through the long-term operation of power systems at home and abroad, we have accumulated a wealth of operation data, cases, experience and so on. The field of disaster prevention and emergency response of the whole society has also experienced various tests. This kind of experience is interlinked, which can be used for reference between power system and other social systems. It is a bridge between power system disaster prevention and emergency response and social disaster prevention and emergency response.

A large number of emergency personnel have been trained. Because of the importance of safety, the power system has trained a large number of emergency personnel. These talents have the basic quality of disaster prevention and emergency response and the professional quality of power system disaster prevention and emergency. They can effectively support the social disaster prevention and emergency response.

It has strong policy support. The state has successively promulgated a series of laws, regulations and various plans, such as the law of the people's Republic of China on safety of production, the regulations on reporting and investigation and handling of production safety accidents, and the emergency plan for the state to deal with large-scale power outage events of power grid. These laws, regulations and various plans provide policy guarantee for the integration of disaster prevention and emergency response of power system into social disaster prevention and emergency response.

\section{Integration path}

\subsection{Basic mode}

According to the degree of integration, the integration of power system disaster prevention and emergency into society can be divided into three basic modes: weak connection mode, merge mode and unified coordination mode.

1) Weak connection mode. In this way, the power system remains relatively independent. And the connection with the social disaster prevention and emergency system is relatively weak. In the actual operation, the two sides share less data, loose contact, poor linkage.

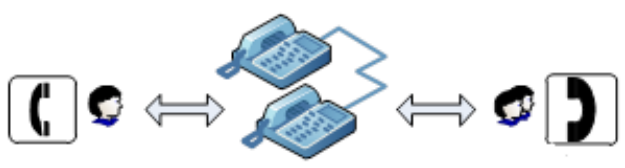

Fig. 1. Weak connection mode

2) Merge mode. In this mode, the power system disaster prevention and emergency system is directly 
integrated into the social disaster prevention and emergency system. It no longer exists as an independent system.

3) Unified coordination mode. In this mode, the power system disaster prevention and emergency as a subsystem of the whole society disaster prevention and emergency system. The professional characteristics of the power system can be maintained to a certain extent. The two sides share more data, close contact, good linkage.

\subsection{Integration process}

From the above analysis, it can be seen that the weak connection mode has low cost, few changes to each party's system, and is easy to realize, but it has limited effect on improving the disaster prevention and emergency response level of all parties, and can be used as a transition mode in the early stage of integration. The unified coordination mode effectively solves the contradiction between maintaining the professionalism of power system and improving the level of disaster prevention and emergency response after integration, which is the goal of integrated development in the future. The integration mode has high requirements on software, hardware and operation management level of all parties, which is the long-term development goal.

\section{Case study}

\subsection{Simulation model}

In this paper, the simulation model is built. It simulates IEEE 39 bus system. IEEE 39 bus system has 39 nodes, 46 lines and 10 generator units. Generator units at nodes are represented by capital letter $\mathrm{G}$, and loads at nodes are represented by arrows, as shown in the figure below.

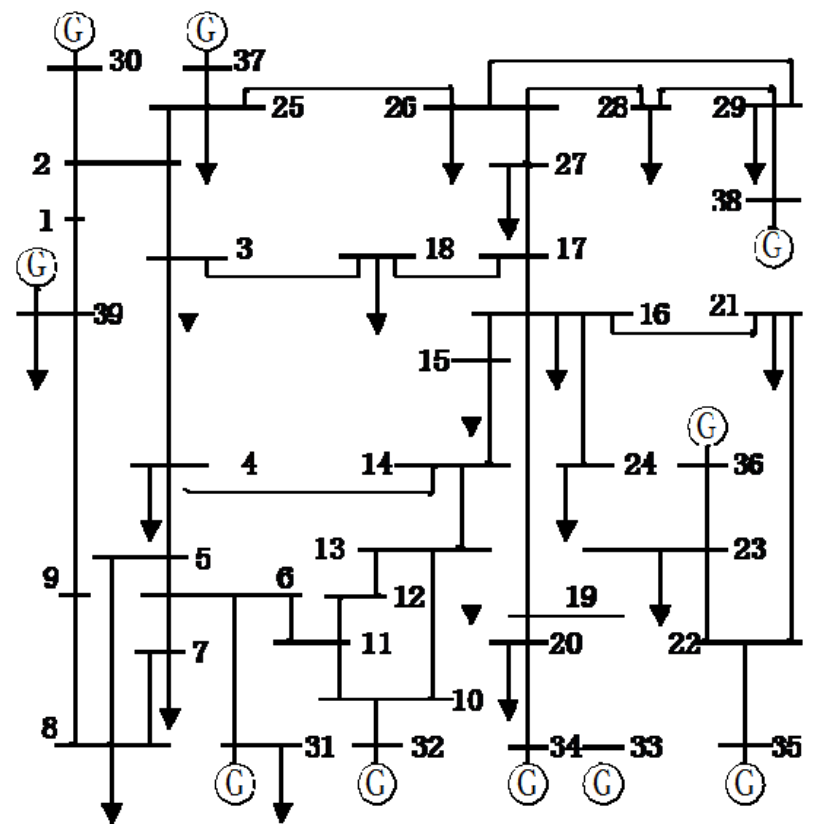

Fig. 2. Schematic of IEEE 39-bus system

\subsection{Simulation results and analysis}

The power system operates normally, and the load of node 29 is supplied by line L26-29, 128-29 and generator g38. The mountain fire disaster occurred at 13:26 p.m. and gradually spread. At 14:16 p.m., the mountain fire spread to the lower part of line 126-29. Thick smoke and high temperature caused the trip of line L26-29. The load of node 29 was supplied by line L28-29 and generator G38. At this time, the area where node 29 is located is in hot weather, the air conditioning load rises rapidly in the afternoon, and the active power flow of line L28-29 increases rapidly, resulting in the overload trip of line L28-29. Node 29 and node 38 split from the system to form an isolated system. Because the capacity of G38 generator can't meet the load demand of node 29, it eventually leads to a blackout in this area.

Table 1. Power system emergency response

\begin{tabular}{|c|c|c|c|}
\hline & $13: 26$ & $\begin{array}{c}\text { Before } \\
14: 16\end{array}$ & After 14:16 \\
\hline L26-29 & 1.96 & 0 & 0 \\
\hline L28-29 & 2.07 & 4.03 & 0 \\
\hline P29 & 4.83 & 4.83 & 0 \\
\hline G38 & 0.80 & 0.90 & 0 \\
\hline
\end{tabular}

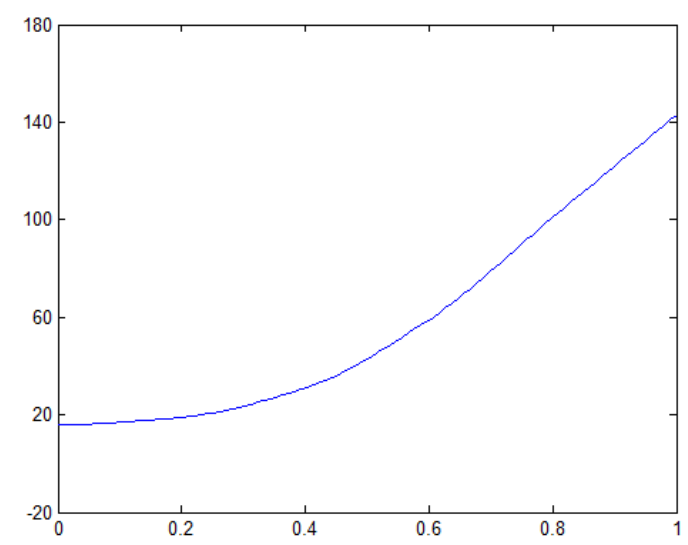

Fig. 3. Angle curves of bus-38 synchronous generator

In the case of whole society emergency, when a mountain fire occurs, the forest department can immediately push early warning information and fire development assessment information to the power department. For high temperature weather, the meteorological department can timely push the forecast information to the power department. The power system can adjust the trend in advance, increase the output of the unit, and reduce the power flow of the line. At the same time, the power system emergency system can also provide information or request support cooperation to the social emergency department. The social emergency department coordinates with the forest emergency department to focus on controlling the fire development 
of the location of the transmission line, and prompts the local residents to prevent the risk of power failure through the social emergency system. It is suggested to increase the set temperature of air conditioning and reduce the power consumption level.

After emergency treatment, line L26-29 tripped at 14:35 PM. Within 19 minutes, the regional load was reduced by $10 \%$, the unit output was increased to full power, and the power flow of line L28-29 was reduced to below the safety threshold of 3.5. The connection between the region and the system was maintained, and the blackout accident was resolved.

Table 2. Social emergency

\begin{tabular}{|c|c|c|c|}
\hline & $13: 26$ & $\begin{array}{c}\text { Before } \\
14: 35\end{array}$ & After 14:35 \\
\hline L26-29 & 1.96 & 0 & 0 \\
\hline L28-29 & 2.07 & 3.35 & 3.35 \\
\hline P29 & 4.83 & 4.35 & 4.35 \\
\hline G38 & 0.80 & 1.00 & 1.00 \\
\hline
\end{tabular}

Comparing the different emergency results before and after the integration of power system emergency into the whole society, it can be seen that after the integration of power system emergency into the whole society emergency, it can effectively coordinate the emergency forces of all aspects of the whole society, form a joint force, create a foundation for power system emergency and win precious time.

\section{Conclusion}

It is necessary and feasible to integrate power system disaster prevention and emergency into social disaster prevention and emergency. Through the integration of all parties, it can reduce redundant construction. And investment is saved. The disaster prevention and emergency capacity of the power system is improved. So as to improve the disaster prevention and emergency capacity of the whole society.

There are three modes of integrating power system disaster prevention and emergency into social disaster prevention and emergency: weak connection mode, merging mode and unified coordination mode. The path of integration should be in the form of early weak connection integration, mid-term unified coordination and long-term full integration.

The research focuses on the theoretical basis demonstration and mode selection of the integration of power system disaster prevention and emergency response into social disaster prevention and emergency response, while the specific operation level of integration is only preliminarily discussed. In the future, it is necessary to conduct in-depth research on the process, regulations, legislation and other aspects.

\section{Acknowledgements}

The acknowledgements: this paper is supported by the Fundamental Research Funds for the Central Universities (3142020014) and the Fundamental Research Funds for the Central Universities (3142019055).

\section{References}

1. Do Yang Jung, Baek Haeng Lee, Sun Wook Kim. Development of battery management system for nickel-metal hybrid batteries in electric vehicle applications. Journal of Power Sources, 109, 110(2002).

2. John Chatzakis, Kostas Kalaitzakis, Nicholas C Voulgaris,et al. Designing a New Generalized Battery Management System. IEEE Transactions on Industrial Electronics, 50, 9-15(2003).

3. Josep M. Guerrero, Luis García de Vicuña, José Matas, Miguel Castilla, and Jaume Miret. A wireless controller to enhance dynamic performance of parallel inverters in distributed generation systems. Power Electronics, 19, 1205-1213(2004).

4. Blyden. BK, Wei-Jen Lee. Modified microgrid concept for rural electrification in Africa. Power Engineering Society General Meeting, 2, 1822(2006).

5. M. Barnes, A. Dimeas, A. Engler, C. Fitzer, N. Hatziargyriou, C. Jones, S. Papathanassiou, M. Vandenbergh. MicroGrid Laboratory Facilities, Future Power Systems. International Conference, 1, 1-6(2005).

6. Funabashi. T, Yokoyama.R. Microgrid field test experiences in Japan. IEEE Power Engineering Society General Meeting, 3, 1-2(2006).

7. Benjamin Kroposki, Christopher Pink, Thomas Basso and Richard DeBlasio. Microgrid Standards and Technology Development. IEEE Power Engineering Society General Meeting, 3, 1-4(2007).

8. R. Majumder, A. Ghosh, G. Ledwich, F. Zare. Load sharing and power quality enhanced operation of a distributed microgrid. Renewable Power Generation, 16, 109 - 119(2009).

9. Chien-Liang Chen, Yubin Wang, Jih-Sheng Lai. Design of Parallel Inverters for Smooth Mode Transfer Microgrid. Applications Applied Power Electronics Conference and Exposition, 12, 1288 1294(2009).

10. J. Eto, R. Lasseter, B. Schenkman and J. Stevens, et al. Overview of the CERTS Microgrid laboratory Test Bed. Integration of Wide-Scale Renewable Resources Into the Power Delivery System, 5, 1219(2009). 